\title{
CONSTRUÇÃO DE CONHECIMENTO SOBRE O TEMA AVALIAÇÃO DE DESEMPENHO DA COMUNICAÇÃO EM ÓRGÃOS PÚBLICOS: UMA ANÁLISE DA LITERATURA INTERNACIONAL
}

\section{RESUMO}

O objetivo deste estudo é analisar as características das pesquisas cientificas internacionais que abordam o fragmento da literatura referente ao tema Avaliação de Desempenho da Comunicação em órgãos públicos. A metodologia utilizada é exploratória descritiva, quali-quanti e utiliza o instrumento Knowledge Development Process-Constructivist (ProKnowC) para definição do Portifólio Bibliográfico e Análise Bibliométrica. Os resultados da pesquisa evidenciam: (i) A seleção de um Portifólio Bibliográfico composto por 29 artigos; (ii) Os periódicos de maior destaque "Public Performance \& Management Review" e "Public Administration Review"; (iii) Dentre os artigos 63\% utilizam sistemas de mensuração de desempenho e 37\% de gestão de desempenho; e, (iv) a maior parte (55\%) encontram-se em um estágio evolutivo de "transição de operações para as orientações estratégicas", percebe-se a adoção de modelos de avaliação realistas, obtidos de forma genérica, sem levar em conta as particularidades dos contextos avaliados e dos atores inseridos no processo decisório.

Palavras-chave: Avaliação de Desempenho; Gestão Pública; ProKnow-C.

\section{CONSTRUCTION OF KNOWLEDGE ABOUT THE THEME PERFORMANCE EVALUATION OF COMMUNICATION IN PUBLIC ORGANS: AN ANALYSIS OF INTERNATIONAL LITERATURE}

\begin{abstract}
The goal of this study is to analyze the characteristics of the international scientific researches that approach the fragment of the literature on the subject of Evaluation of Performance Communication in public agencies. The methodology is exploratory, descriptive and quali-quantitative approach and uses as instrument the Knowledge Development Process-Constructivist (ProKnow-C) to define the Bibliographic Portfolio and Bibliometric Analysis. The results highlight: (i) The selection of a Bibliographic Portfolio composed of 29 articles; (ii) The most prominent journals are "Public Performance \& Management Review" and "Public Administration Review"; (iii) Among the papers, $63 \%$ use performance measurement systems and $37 \%$ performance management systems; and, (iv) The majority $(55 \%)$ is in an evolutionary stage of "transition from operations to the strategic orientations". The adoption of realistic evaluation models is noticeable, obtained in a generic form, without taking into consideration the particularities of the contexts and the actors involved in the decision process.
\end{abstract}

Keywords: Performance Evaluation; Public Management; ProKnow-C. 


\section{CONSTRUCCIÓN DE CONOCIMIENTO SOBRE EL TEMA EVALUACIÓN DE DESEMPEÑO DE LA COMUNICACIÓN EN ÓRGANOS PÚBLICOS: UN ANÁLISIS DE LA LITERATURA INTERNACIONAL}

\section{RESUMEN}

El objetivo de este estudio es analizar las características de las investigaciones científicas internacionales que abordan el fragmento de la literatura referente al tema Evaluación de Desempeño de la Comunicación en órganos públicos. La metodología utilizada es exploratoria descriptiva, cuali-quanti y utiliza el instrumento Knowledge Development Process-Constructivist (ProKnow-C) para definición del Portafolio Bibliográfico y Análisis Bibliométrico. Los resultados de la investigación evidencian: (i) La selección de un Portafolio Bibliográfico compuesto por 29 artículos; (ii) Los periódicos más destacados de Public Performance \& Management Review y Public Publication Review; (iii) Entre los artículos $63 \%$ utilizan sistemas de medición de desempeño y 37\% de gestión de desempeño; y (iv) la mayor parte $(55 \%)$ se encuentran en una etapa evolutiva de "transición de operaciones hacia las orientaciones estratégicas", se percibe la adopción de modelos de evaluación realistas, obtenidos de forma genérica, sin tener en cuenta las particularidades de los contextos evaluados y de los actores insertados en el proceso decisorio.

Palabras clave: Evaluación de Desempeño; Gestión Pública; ProKnow-C.

Leonardo Ensslin ${ }^{1}$ Luiz Antonio Giardino Graziano ${ }^{2}$ Ademar Dutra ${ }^{3}$ Vinicius Dezem ${ }^{4}$

\footnotetext{
${ }^{1}$ Doutor em Engenharia Industrial e Sistemas pela University of Southern California, Estados Unidos. Professor da Universidade do Sul de Santa Catarina - UFSC. Brasil. E-mail: leonardoensslin@gmail.com

${ }^{2}$ Pós-graduado em Administração em Segurança Pública pela Universidade do Sul de Santa Catarina - UNISUL. Brasil. E-mail: luizgraziano@hotmail.com

${ }^{3}$ Doutor em Engenharia de Produção pela Universidade Federal de Santa Catarina - UFSC. Vice-Coordenador da Universidade do Sul de Santa Catarina - UNISUL. Brasil. E-mail: ademar.unisul@gmail.com

4 Mestre em Administração pela Universidade Do Sul De Santa Catarina - UNISUL. Brasil. E-mail: vinicius_dezem@hotmail.com
} 


\section{INTRODUÇÃO}

A Avaliação de Desempenho tem sido usada com frequência na gestão pública, possibilitando a evolução dos processos e o desenvolvimento das organizações. Obteve destaque nas décadas de 80 e 90, sobre tudo em função dos modelos de gestão que surgiram em alguns países, como Grã-Bretanha e Nova Zelândia, cuja ênfase era o aumento da eficiência do Estado na prestação de serviços públicos (RADEBE, 2015). De acordo com Brignall e Modell (2000), um dos objetivos da Administração Pública é satisfazer as necessidades da sociedade em geral, incluindo todos aqueles que se relacionam ou dela dependem. Inclui-se, portanto, o governo, os administradores públicos, os servidores públicos e a sociedade em geral (WHITELEY et al., 2016).

Para o alcance destes objetivos a Administração Pública faz uso da Avaliação de Desempenho, estando sua importância no uso que dela se faça, ou seja, sua utilidade está nas providências que serão tomadas pelos gestores em relação àquilo que for revelado durante o processo de Avaliação de Desempenho (FLEISHER \& MAHAFFY, 1997).

A comunicação torna-se fundamental neste processo, por seu potencial de incentivo às mudanças culturais relacionadas as orientações estratégicas das organizações (MELKERS, 2006). Sua importância se deve ainda a relação com o público externo, por meio da transparência e da divulgação de objetivos e ações possibilitando o estabelecimento de relação de confiança entre sociedade e governo (KIVIMAKI, 2000; ZHANG \& CHEN, 2015).

A avaliação de desempenho da comunicação é pouco utilizada por governos na gestão pública. É inegável a importância da avaliação de desempenho da área de comunicação, Fleisher e Mahaffy (1997) afirmam que poucos gestores têm à disposição um sistema eficiente de avaliação de desempenho da comunicação e enfrentam problemas na gestão pelo fato de alguns operadores do sistema de comunicação alegarem que o que fazem não pode ser medido. São raros os estudos que avaliam o desempenho da comunicação dos órgãos públicos, sobretudo o desenvolvimento de modelos personalizados.

Dada a importância da avaliação de desempenho do processo de comunicação dos órgãos públicos, o intuito dessa pesquisa é responder à seguinte pergunta: Quais as características das publicações científicas sobre o tema avaliação de desempenho do processo de comunicação dos órgãos públicos?

Para responder essa pergunta, tem-se como objetivo analisar as características das pesquisas científicas internacionais que abordam o fragmento da literatura referente à avaliação de desempenho da comunicação em órgãos públicos, bem como o estágio evolutivo destas pesquisas, visando a geração de conhecimento e contribuições para a evolução do tema. Como instrumento de intervenção para as etapas de seleção do Portfólio Bibliográfico (PB) e análise bibliométrica utilizou o ProKnow-C (Knowledge Development Process-Constructivist).

Esta pesquisa justifica-se pela importância, originalidade e viabilidade (CASTRO, 1977). É importante porque, a partir da identificação e análise das características das publicações deste fragmento da literatura e do conhecimento gerado, é possível sintetizá-lo em diretrizes para novas pesquisas. Entende-se original por não ter sido encontrado, na literatura consultada, artigo que realizasse análise do alinhamento entre a base epistemológica e a evolução do conhecimento sobre sistemas de avaliação de desempenho da comunicação em órgãos públicos. A viabilidade é aferida devido ao acesso aos dados, visto que os artigos que serão objetos de análise são buscados no portal de periódicos da CAPES e pela disponibilidade e empenho dos pesquisadores para a coleta dos dados, sua leitura e análise.

Além da seção introdutória, este artigo apresenta o referencial teórico sobre avaliação de desempenho da comunicação em órgãos públicos na seção 2; na seção 3 é apresentada a metodologia da pesquisa; os resultados são apresentados na seção 4; na seção 5 são apresentadas as considerações finais e, por fim, as referências de base para este trabalho são apresentadas.

\section{REFERENCIAL TEÓRICO}

Nesta seção serão apresentados conceitos relevantes para expansão do conhecimento sobre o tema Avaliação de Desempenho do Processo de Comunicação em Órgãos Públicos, utilizando os artigos do Portfólio Bibliográfico internacional, decorrente desta pesquisa.

\subsection{Avaliação De Desempenho}

No início do século XX a Avaliação de Desempenho limitava-se a medir o desempenho das pessoas a partir de métodos realistas. Os padrões de produtividade, tempo e qualidade ditavam as regras para definir se os processos de produção eram ou não eficientes, ou seja, o desempenho tinha um viés eminentemente operacional. A partir do desenvolvimento dos sistemas de avaliação de desempenho e as novas demandas do mercado, a avaliação de desempenho deixa de se preocupar apenas com aspectos operacionais e evolui para aspectos estratégicos, de gestão e com enfoque na visão dos stakeholders (ENSSLIN et al., 2016).

A diversidade de definições para esta área de conhecimento, e as lacunas existentes na via do apoio a decisão, fez com que Ensslin et al., (2010, p. 130) 
definissem a seguinte conceituação para a avaliação desempenho, como um instrumento de apoio à decisão:

\begin{abstract}
Avaliação de Desempenho é o processo para construir conhecimento no decisor, a respeito do contexto específico que se propõe avaliar, a partir da percepção do próprio decisor por meio de atividades que identificam, organizam, mensuram ordinalmente e cardinalmente, integram e permitem visualizar o impacto das ações e seu gerenciamento. (ENSSLIN et al., 2010, p. 130).
\end{abstract}

A partir deste entendimento, a Avaliação de Desempenho é vista como um instrumento de gestão aplicado para construir, fixar e expandir conhecimento de formas a permitir monitorar e aperfeiçoar o contexto que o decisor deseja realizar a gestão. Esta é a principal responsabilidade dos sistemas de Avaliação de Desempenho com enfoque Construtivista (ENSSLIN et al.,2010).

O caminho Construtivista é indicado para o apoio à gestão de contextos singulares e complexos, porém por suas recentes origens na avaliação de desempenho e demandar conhecimentos qualitativos e quantitativos de múltiplas áreas é pouco conhecido pela maioria dos pesquisadores tendo seu uso em função disto mais limitado na gestão pública (ROY, 1993).

A avaliação de desempenho do órgão público se dá mediante a análise de indicadores de desempenho, estes evidenciam pontos que devem ser tratados pelos gestores, não só para fins de acompanhamento e controle, mas principalmente para orientação e direcionamento de ações de melhoria. A adoção de indicadores como ferramentas de suporte à tomada de decisão minimiza a subjetividade na percepção do valor das ações pelos gestores, permite deliberar com lucidez e objetividade acerca da aplicação das verbas públicas além de possibilitar a clara comunicação para os contribuintes sobre as práticas de gestão e investimentos (JOHNSEN, 2005; RADEBE, 2015).

\subsection{Avaliação De Desempenho Do Processo De Comunicação Em Órgãos Públicos}

A comunicação é uma importante ferramenta para os gestores atingirem seus objetivos estratégicos em relação ao público interno e externo. Apesar disso, a avaliação de desempenho do processo de comunicação em órgão públicos não é prática comum. Segundo Fleisher e Mahaffy (1997) todas as áreas das organizações devem estar envolvidas no processo de atendimento das demandas dos clientes/usuários, sobretudo atualmente, quando o mercado encontra-se extremamente competitivo, reconhecendo que a qualidade do trabalho é que vai determinar a diferença na forma como os clientes se comportam e respeitam a organização. A área de comunicação das organizações contempla oportunidades de contribuir na mensuração de desempenho, mas antes essa área deve melhorar sua capacidade de gestão em avaliação de desempenho, ou seja, os profissionais de comunicação precisam demonstrar seu valor e efetividade nos negócios, seja na forma de atividades, produtos, serviços ou programas (JOHNSEN, 2005).

Executivos da área de comunicação reconhecem que sistemas de avaliação de desempenho são essenciais dentro de uma visão estratégica e que proporcionarão aos gestores saber se os objetivos foram alcançados e como o foram. Os resultados dos sistemas de avaliação permitirão aos gestores verificar quais valores estão sendo criados ou adicionados aos processos ou aos produtos, onde devem ser feitas melhorias e investimentos e onde as estratégias estão sendo implementadas com sucesso ou não. Além disso, a avaliação de desempenho da área de comunicação permitirá ao gestor verificar como estão sendo aplicados os recursos financeiros, humanos, materiais e de tempo dessa área. Entretanto, boa parte dos profissionais desta área acreditam que os sistemas de avaliação não fornecem as informações necessárias para bem avaliar e gerenciar a área, sob o argumento que a área é complexa e misteriosa, devendo sua avaliação e gestão ser conduzida somente por profissionais da área de comunicação e que os gestores não conseguem entender as contribuições da área de comunicação para as empresas (FLEISHER \& MAHAFFY, 1997).

Os autores sugerem, ainda, que o sistema de avaliação de desempenho englobe aspectos ou indicadores financeiros, não financeiros, quantitativos, qualitativos e mensurações de resultados e processos, devendo a avaliação de desempenho ser descritiva e prescritiva. Ao final do trabalho, os autores sugerem que não se estabeleça um único método ou forma de avaliação de desempenho da comunicação, porquanto, isso depende do contexto, cultura e complexidade do trabalho ou processo em análise. O processo de avaliação de desempenho deverá ser construído de acordo com os interesses da organização, mas independentemente do tipo de abordagem (FLEISHER \& MAHAFFY, 1997; JOHNSEN, 2005; RADEBE, 2015).

Neste contexto, o desenvolvimento de sistemas de avaliação de desempenho da comunicação em órgãos públicos, tendo como alvo os públicos interno e externo, constitui-se como oportunidade de possuir uma ferramenta que auxilie a gestão pública.

\subsection{Processos Evolutivos Das Práticas De Avaliação De Desempenho}

Em seus estudos, Srimai, Radford e Wright (2011) afirmam que a Avaliação de Desempenho percorre quatro caminhos evolutivos, os quais passam do operacional às orientações estratégicas, para os domínios da gestão, do estático para o dinâmico e do 
acionista para os stakeholders, e podem ser classificados da seguinte forma:

a) Transição de operações para as orientações estratégicas, onde a medição de desempenho passou de um nível de operações para um foco na sustentação estratégica, buscando vantagem competitiva. Esta nova noção de medição de desempenho significa a ideia de que medição do desempenho e estratégia estão estreitamente ligados, passando a ser chamada de medição de desempenho estratégica.

b) Transição de medição para domínios de gestão, onde a medição de desempenho expandiu o seu papel histórico de implementação da estratégia para facilitar a gestão estratégica. O foco mudou para "a forma de gerir o que é medido" como um meio para garantir que, o que é medido será implementado com êxito. A justificativa de sistemas de gestão de desempenho como sistemas de gestão da estratégia é que eles incorporam uma capacidade superior para competir nos mercados, ou seja, os sistemas de medição de desempenho estão se esforçando para proporcionar processos para identificar, monitorar, diagnosticar, comunicar e gerar informações estratégias com a finalidade de gerir pessoas e recursos, e com isso responder a um mercado competitivo.

c) Transição de estático para perspectivas dinâmicas, no qual a alta administração redireciona a atenção para sistemas e processos organizacionais dinâmicos, ao invés de rígidas estruturas, de forma a responder prontamente ao mercado - para assegurar a sustentabilidade dinâmica da empresa. Os papéis dinâmicos de medição de desempenho no ciclo de gestão, envolvem o planejamento, a execução e o monitoramento, de forma contínua.

d) Transição do acionista aos valores das partes interessadas, onde a comunidade empresarial e científica tende a associar a medição de desempenho, atualmente, a satisfação das demandas dos stakeholders.

A mensuração do desempenho tem o papel de direcionar ações de melhoria, apontando os pontos de atenção, sobre os quais devem ser envidados os maiores esforços e aplicados mais recursos, seja para fomentar o aproveitamento de oportunidades, seja para minimizar impactos externos negativos ou otimizar o reflexo das estratégias idealizadas sobre os processos organizacionais (SINCLAIR \& ZAIRI, 2001).

Levando em conta a necessidade de medir o desempenho das organizações Melnyk et.al. (2014) afirmam que a medição de desempenho e gestão é fundamental para a gestão eficiente de qualquer negócio e facilita a implementação da estratégia e melhora o desempenho organizacional.

Os autores classificam a medição de desempenho e gestão em dois sistemas: a) Sistema de medição de desempenho e b) Sistema de gestão de desempenho. O sistema de medição de desempenho caracteriza-se por definir objetivos (desenvolvimento do conjunto de métricas) e coleta, análise e interpretação de dados de desempenho. O objetivo do processo é converter dados em informações e para avaliar a eficácia e eficiência da ação (NEELY, GREGORY \& PLATTS, 1995).

Embora a medição do desempenho seja importante, não é suficiente para gerir uma empresa. $\mathrm{O}$ sistema de gestão de desempenho engloba o processo de avaliar as diferenças entre os resultados reais e desejados, identificar e sinalizar aquelas diferenças que são críticas (garantindo assim a intervenção de gestão).

\section{MÉTODO}

A metodologia da pesquisa contempla o enquadramento metodológico e o instrumento utilizado para geração de conhecimento, coleta e análise dos dados.

\subsection{Enquadramento Metodológico}

O enquadramento da pesquisa caracteriza-se, em exploratória descritiva. É exploratória por promover e expandir o conhecimento dos pesquisadores referente ao fragmento da literatura estudado e descritiva, porque um dos objetivos é descrever as características de determinada população ou fenômeno e, no caso pesquisado, pretende-se descrever as características e destaques do PB (TRIVIÑOS, 2015). Quanto à abordagem da pesquisa, este estudo utiliza a qualitativa e quantitativa, consideram-se as premissas do instrumento ProknowC. Nas etapas qualitativas, os pesquisadores examinam e refletem de acordo com suas percepções a fim de obter um entendimento quanto ao tema pesquisado, já na fase quantitativa, as variáveis investigadas do PB são analisadas por meio da Análise Bibliométrica (CRESWELL, 2010).

Para a coleta de dados utilizou-se dados primários e secundários. Na seleção de artigos para formação do PB utiliza dados primários, uma vez que as delimitações são realizadas pelos pesquisadores em todas as escolhas necessárias durante o processo. $\mathrm{Na}$ fase de análise bibliométrica - identificação e análise 

Públicos: Uma Análise da Literatura Internacional

dos destaques das características do PB - utilizou dados secundários (ROSA et al., 2015).

A pesquisa é, quanto aos fins, aplicada, de acordo com Beuren (2003), consiste na utilização dos conhecimentos já disponíveis para alguma utilização prática, ou seja, os resultados obtidos são pretendidos como de aplicação imediata para a resolução de problemas da realidade. Em relação aos procedimentos técnicos a pesquisa é classificada como bibliográfica, considerando que a busca é constituída pela pesquisa em referências sobre o tema a ser estudado com artigos científicos disponibilizados na base de dados da Coordenação de Aperfeiçoamento de Pessoal de Nível Superior (CAPES).

\subsection{Instrumento De Intervenção - Knowledge Development Process - Contructivist (Proknow-C)}

O instrumento de intervenção utilizado é o ProKnow-C (Knowledge Development Process Constructivist) (ENSSLIN et al., 2010), que tem como objetivo construir conhecimento no pesquisador a respeito de um tema específico que este esteja estudando.

Nos últimos anos, diversos trabalhos vêm sendo publicados em diferentes áreas de conhecimento, informados pelo ProKnow-C, para: (i) identificar um fragmento da literatura relevante sobre o tema de interesse do pesquisador (Portfólio Bibliográfico-PB); (ii) conhecer as peculiaridades da área de estudo; (iii) realizar análise crítica desse PB com base na corrente teórica selecionada pelo pesquisador; e (iv) evidenciar lacunas na literatura para subsidiar a formulação de futuros trabalhos ( ENSSLIN \& ENSLIN, 2013; DUTRA et al., 2015; ENSSLIN et al., 2015; ROSA et al., 2015; ENSSLIN, ENSSLIN \& PINTO, 2013; e TASCA et al., 2010). A figura 1 apresenta as quatro etapas que compreendem o ProKnow-C.

Figura 1 - Etapas do ProKnow-C

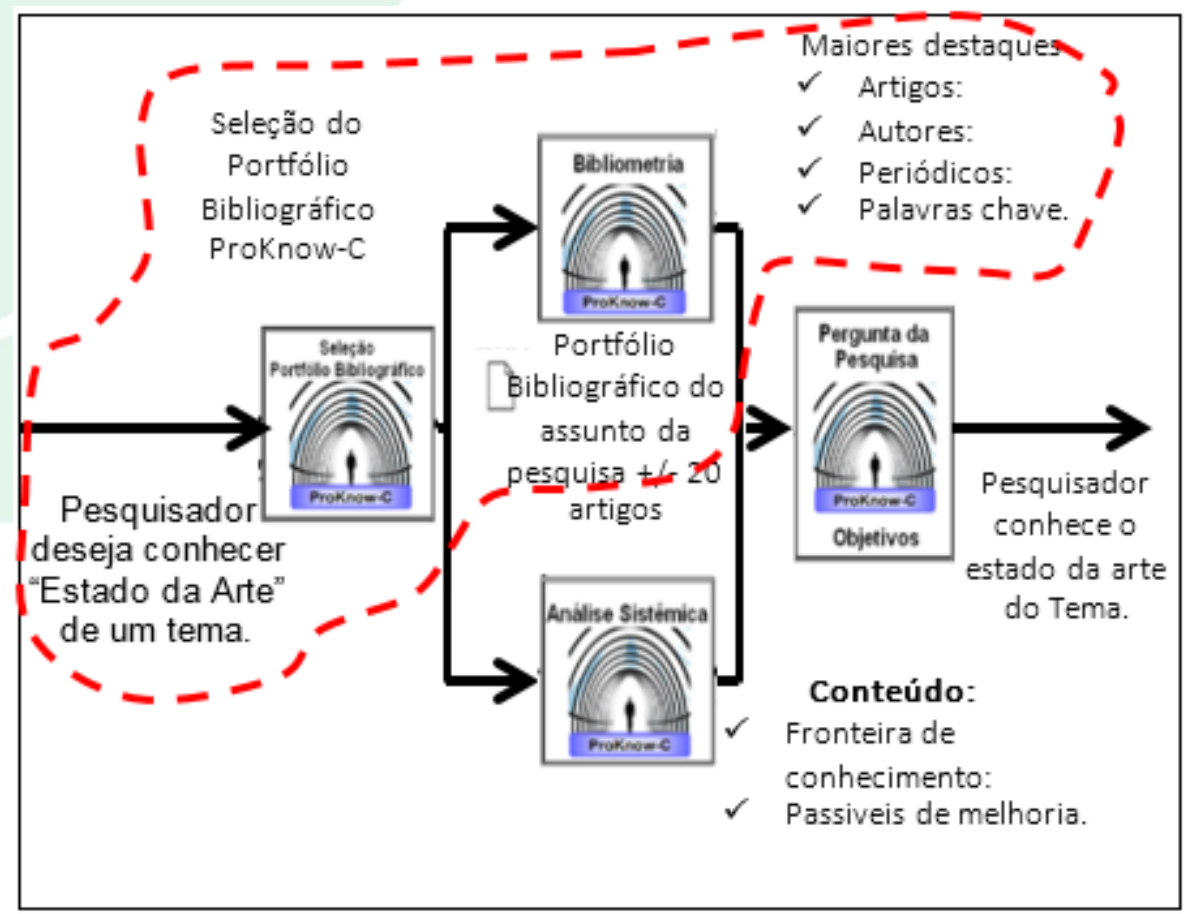

Fonte: Adaptado de Tasca, et al., (2010).

A seguir será apresentado os procedimentos utilizados para a seleção do portfólio bibliográfico referente ao fragmento da literatura Avaliação de Desempenho da Comunicação em órgãos públicos.

\subsection{Procedimentos Para Seleção Do Portifólio Bibliográfico $(\mathbf{P b})$}

Para o alcance do objetivo desta pesquisa, fez-se necessária a seleção do PB - etapa (i) do ProKnow-C. A Figura 2 ilustra de forma geral e ampla a operacionalização desta etapa de seleção de artigos do PB que representam o fragmento da literatura sobre avaliação de desempenho da comunicação em órgãos públicos.

Para a iniciação do processo do ProKnow-C, é necessário a decisão de qual o tema que o pesquisador quer construir um conhecimento e a partir deste devem ser definidos os eixos de pesquisa e palavras-chave, no presente estudo os eixos de pesquisa foram (i) Avaliação de desempenho e (ii) Comunicação social. Após a definição dos eixos de pesquisa, é necessário 
definir quais as palavras-chave a serem utilizadas na busca dos artigos nas bases de dados da CAPES. Considerando que o eixo 2 tratará da comunicação social, e o interesse está voltado à comunicação em órgãos públicos, definiu-se que uma das palavras-chave do eixo 2 seria "public".

Após tal definição, a próxima etapa é seleção do portfólio de artigos brutos, e sequencialmente a filtragem do banco de artigos selecionados (ENSSLIN et al., 2015). Tais palavras-chaves serão combinadas, a fim de formarem todas as combinações possíveis para a coleta de artigos. As palavras destacadas acima formaram a expressão booleana ("Performance evaluation" OR "Performance management" OR "Performance assessment" OR "Performance measurement") AND ("Public relationship" OR "communication").
A busca pelos artigos é realizada utilizando-se das combinações das palavras-chave nos títulos dos artigos (Article Titles), resumos (Abstracts) e nas palavras-chave (Keywords), nas bases de dados selecionadas. A busca foi realizada nas bases de dados da CAPES no período de abril de 2016. A área de interesse da pesquisa foi Ciências Sociais Aplicadas. Após alguns testes nas bases existentes na área do conhecimento "Ciências Sociais Aplicadas", definiu-se as seguintes bases de dados aderentes ao tema: EBSCO, ISI Web of Knowledge (WEB of Science), PROQUEST, SCOPUS, ScienceDirect e WILEY. Após a realização da busca dos artigos científicos nas 6 (seis) bases de dados já mencionadas, obtivemos um total de 5.840 artigos, conforme apresentado na Figura 2.

Figura 2 - Resultado da busca de artigos nas Bases de Dados

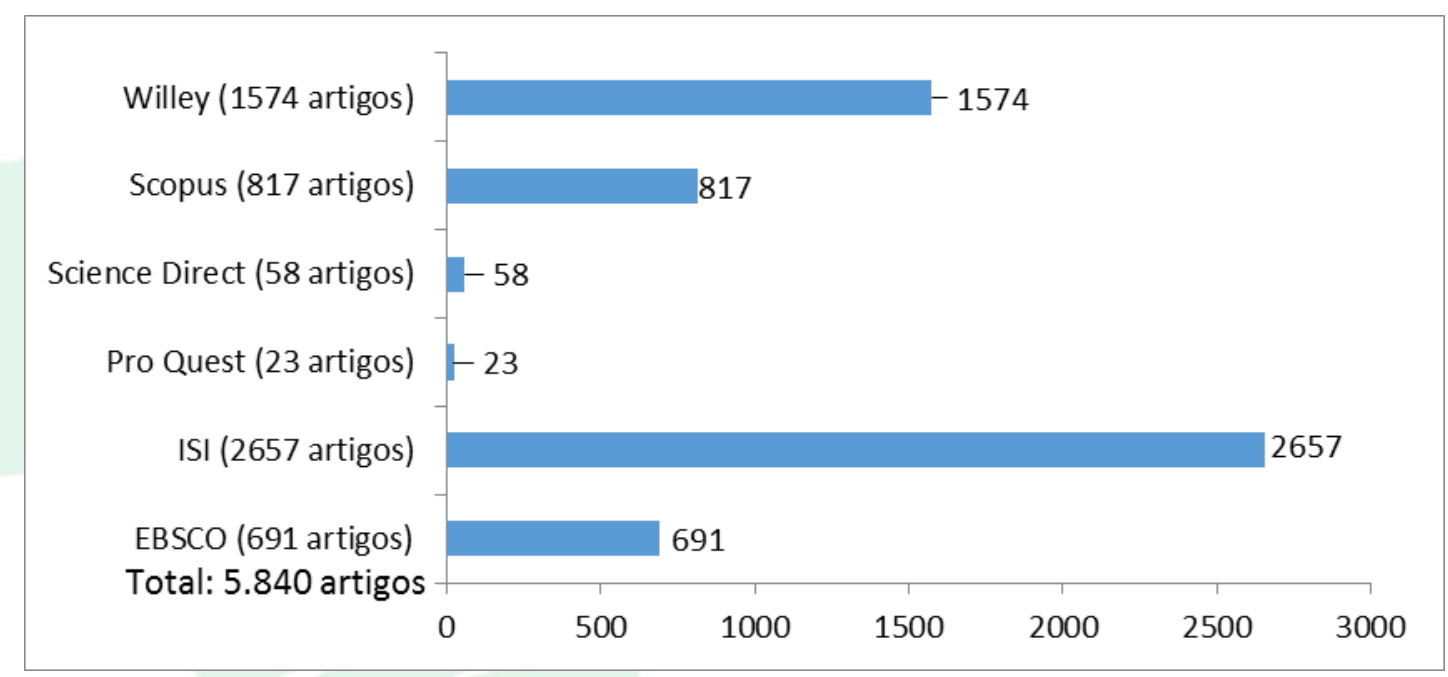

Fonte: Autores da pesquisa (2017).

A base com maior retorno foi a ISI (Web Of Science), com 2.657 artigos, e, a de menor retorno a Pro Quest, com 23 artigos. Após a seleção dos artigos é aplicado o teste de aderência das palavras chave, o qual consiste na verificação se as palavras utilizadas estão em consonância com os artigos solicitados, verificando também a necessidade ou não de inclusão de alguma palavras-chave (ENSSLIN et al., 2015). Foram escolhidos três artigos alinhados ao tema de pesquisa pelo título e foram confrontadas as palavras chaves desses artigos com as palavras chave da pesquisa. Verificou-se que os artigos selecionados possuem as palavras chave desejadas, confirmando-se a aderência. Para a presente pesquisa, não foi necessária a inclusão de novas palavras-chaves, portanto, o banco de artigos bruto está concluído, passando para a fase de filtragem desse banco.

\subsection{Filtragem do Banco de Artigos Bruto} alguma forma compuseram os 5.840 artigos do banco de dados bruto, e que não estão de acordo com os interesses do pesquisador. Portanto, foram realizadas as seguintes etapas conforme destacado por Ensslim et al., (2015): (i) foram excluídos, os livros, seções de livros, seriais, patentes, além dos artigos redundantes, os quais foram exportados de mais de uma base, totalizando 568 exclusões; (ii) posteriormente, a esta exclusão, tem-se 5.272 artigos do total de 5.840. Assim, é observado o alinhamento dos títulos com o tema de interesse. Após esse alinhamento, 70 artigos permaneceram no banco de artigos; (iii) destes, observa-se se há reconhecimento pela comunidade científica dos artigos. Tal reconhecimento foi verificado com base no Google Scholar, o qual apresenta quando da digitação do título do artigo, o total de citações do mesmo. Com isso, são listados os artigos por ordenação de quantidade de citações do mesmo; (iv) na quarta fase de filtragem, realiza-se a verificação dos resumos dos artigos, se 
estes estão alinhados com a pesquisa; e, por fim, (v) realização da leitura integral dos artigos, para confirmação do alinhamento do mesmo com o tema. Ressalta-se que cada uma das etapas listadas anteriormente são de competência eliminatória dos artigos.

Quando da realização da avaliação do reconhecimento científico dos artigos, classificam-se os artigos com reconhecimento científico confirmado ou ainda não confirmado. Para tanto, é realizado o teste de representatividade desejada, o qual foi fixado em 95\% de representatividade. Portanto, considerou-se com reconhecimento científico confirmado aqueles artigos que somassem $95 \%$ do total de citações da amostra, ou seja, os artigos com citações iguais ou superiores a 13. Assim, na pesquisa, classificaram-se 32 artigos com reconhecimento científico e 38 artigos formaram o repositório "P", o qual consiste em artigos que ainda não possuem reconhecimento científico confirmado. Logo, obteve-se o repositório " $K$ " e o repositório " $\mathrm{P}$ ".

Do repositório " $\mathrm{K}$ ", foram lidos os resumos dos artigos científicos, com o intuito de definir se os mesmos estavam alinhados com o tema buscado pelos pesquisadores. Dos 32 artigos pertencentes ao repositório " $\mathrm{K}$ ", 29 artigos foram selecionados como alinhados pela leitura do resumo pelos pesquisadores, eliminando-se 3 artigos. Os 29 artigos selecionados passaram a integrar o repositório "A". Desses repositório foram identificados 67 (sessenta e sete) autores, os quais formaram o Banco de Autores (BA).

Os artigos pertencentes ao repositório "P" (artigos sem reconhecimento científico confirmado) foram filtrados quanto a temporalidade, ou seja, se eram artigos recentes ( 2 anos ou menos) ou se no seu banco possuíam autores que pertenciam ao repositório A. Dos 38 artigos presentes nesse repositório, 7 eram recentes e um artigo era de autor que constava no banco de autores do repositório A. Desse modo, estes 8 artigos foram analisados quando ao alinhamento do resumo. Dos 8 resumos lidos, apenas 3 artigos estavam alinhados à pesquisa, portanto foram eliminados mais 5 artigos, e os 3 alinhados passaram a compor o repositório "C" juntamente com os 29 artigos do repositório "A", totalizando assim um $\mathrm{PB}$ de 32 artigos.

Nesta etapa do processo, verificou-se a disponibilidade dos 32 artigos na íntegra, de forma gratuita e o alinhamento total do artigo ao tema, sendo que 5 artigos foram considerados desalinhados quando da leitura integral dos artigos e 27 foram considerados alinhados. Assim, o portfólio bibliográfico primário ficou composto por 27 artigos.

O Portfólio Bibliográfico (PB) será composto pelo Portfólio Bibliográfico Primário (27 artigos) e pelos artigos que serão selecionados das referências bibliográficas desses 27 artigos. Assim, foram levantadas todas as referências dos 27 artigos, totalizando 1.419 referências. Essas 1.419 referências passaram por uma filtragem, sendo retiradas referências de livros, referências repetidas e foram selecionados 25 artigos pela leitura dos títulos. Foi feita a análise de reconhecimento científico desses 25 artigos, e seguindo todos os padrões adotados anteriormente para seleção do portfólio primário, estabeleceu-se o corte do reconhecimento científico em 13 citações. Assim, 1 (um) artigo apresentou menos que 13 citações. Dos 24 artigos das referências restantes, foram lidos seus resumos, estando todos alinhados. Em seguida passou-se à busca do artigo integral, sendo encontrados apenas 4 (quatro) artigos. Dos 4 artigos lidos integralmente, 2 (dois) estavam totalmente alinhados e passaram a integrar o PB.

Dos 25 artigos das referências, 2 passaram para o PB. O banco de artigos das referências foi composto de 23 artigos e 38 autores. Esses dois artigos oriundos das referências foram somados aos 27 artigos do portfólio Bibliográfico Primário chegando aos 29 artigos do PB e seus 67 autores, o quadro 1 apresenta o PB com autores e títulos: 
Construção de Conhecimento sobre o Tema Avaliação de Desempenho da Comunicação em Órgãos Públicos: Uma Análise da Literatura Internacional

\begin{tabular}{|c|c|c|}
\hline & AUTORES & TITULO \\
\hline 1 & S. Brignall; S. Modell & $\begin{array}{l}\text { An institutional perspective on performance measurement and } \\
\text { management in the 'new public sector' }\end{array}$ \\
\hline 2 & J. Melkers; K. Willoughby & $\begin{array}{l}\text { Models of performance-measurement use in local governments: } \\
\text { Understanding budgeting, communication, and lasting effects. }\end{array}$ \\
\hline 3 & H. Atkinson & Strategy implementation: a role for the balanced scorecard? \\
\hline 4 & S. Schaltegger; M. Wagner & $\begin{array}{llll}\begin{array}{l}\text { Integrative management } \\
\text { measurement and reporting }\end{array} & \text { of sustainability performance, } & \\
\end{array}$ \\
\hline 5 & A. Johnsen & $\begin{array}{l}\text { What Does } 25 \text { Years of Experience Tell Us about the State of } \\
\text { Performance Measurement in Public Policy and Management? }\end{array}$ \\
\hline 6 & L. Pratchett & $\begin{array}{l}\text { New technologies and the modernization of local government: An } \\
\text { analysis of biases and constraints }\end{array}$ \\
\hline 7 & $\begin{array}{l}\text { M. Kivimäki; H. Länsisalmi; } \\
\text { M. Elovainio; A. Heikkilä; } \\
\text { K. Lindström; R. Harisalo; } \\
\text { K. Sipilä; L. Puolimatka }\end{array}$ & Communication as a determinant of organizational innovation \\
\hline 8 & T. H. Poister & $\begin{array}{l}\text { The Future of Strategic Planning in the Public Sector: Linking } \\
\text { Strategic Management and Performance }\end{array}$ \\
\hline 9 & $\begin{array}{l}\text { J. D. Coggburn; S. K. } \\
\text { Schneider }\end{array}$ & $\begin{array}{l}\text { The Quality of Management and Government Performance: An } \\
\text { Empirical Analysis of the American States }\end{array}$ \\
\hline 10 & $\begin{array}{l}\text { S. P. Osborne; T. Bovaird; } \\
\text { S. Martin; M. Tricker; P. } \\
\text { Waterston }\end{array}$ & $\begin{array}{l}\text { Performance management and accountability in complex public } \\
\text { programmes. }\end{array}$ \\
\hline 11 & P. Shanley; C. Lopez & $\begin{array}{l}\text { Out of the Loop: Why Research Rarely Reaches Policy Makers } \\
\text { and the Public and What Can be Done }\end{array}$ \\
\hline 12 & C. S. Fleisher; D. Mahaffy & $\begin{array}{l}\text { A balanced scorecard approach to public relations management } \\
\text { assessment }\end{array}$ \\
\hline 13 & G. A. Boyne; R. M. Walker & $\begin{array}{l}\text { Strategic Management and Public Service Performance: The Way } \\
\text { Ahead }\end{array}$ \\
\hline 14 & E. D. Pulakos; R. S. O’Leary & Why Is Performance Management Broken? \\
\hline 15 & P. Aucoin & $\begin{array}{l}\text { New Political Governance in Westminster Systems: Impartial } \\
\text { Public Administration and Management Performance at Risk }\end{array}$ \\
\hline 16 & M. O'Donnell & $\begin{array}{l}\text { Creating a Performance Culture? Performance-based Pay in the } \\
\text { Australian Public Service }\end{array}$ \\
\hline 17 & $\begin{array}{l}\text { R. F. Speklé; F. H. M. } \\
\text { Verbeeten }\end{array}$ & $\begin{array}{l}\text { The use of performance measurement systems in the public } \\
\text { sector: Effects on performance }\end{array}$ \\
\hline 18 & $\begin{array}{l}\text { G. Jan van Helden; } \AA . \\
\text { Johnsen; J. Vakkuri }\end{array}$ & $\begin{array}{l}\text { Distinctive research patterns on public sector performance } \\
\text { measurement of public administration and accounting disciplines }\end{array}$ \\
\hline 19 & S. E. Kaplan; P. S. Wisner & $\begin{array}{l}\text { The judgmental effects of management communications and a } \\
\text { fifth balanced scorecard category on performance evaluation }\end{array}$ \\
\hline 20 & D. Sinclair; M. Zairi & $\begin{array}{l}\text { An empirical study of key elements of total quality-based } \\
\text { performance measurement systems: A case study approach in the } \\
\text { service industry sector }\end{array}$ \\
\hline 21 & $\begin{array}{l}\text { R. D. Banker; H. Chang; M. } \\
\text { Pizzini }\end{array}$ & $\begin{array}{l}\text { The judgmental effects of strategy maps in balanced scorecard } \\
\text { performance evaluations. }\end{array}$ \\
\hline 22 & $\begin{array}{l}\text { P. Palttala; C. Boano; R. } \\
\text { Lund; M. Vos }\end{array}$ & $\begin{array}{l}\text { Communication Gaps in Disaster Management: Perceptions by } \\
\text { Experts from Governmental and Non-Governmental } \\
\text { Organizations }\end{array}$ \\
\hline 23 & J. Melkers & $\begin{array}{l}\text { On the road to improved performance: Changing Organizational } \\
\text { Communication Through Performance Management. }\end{array}$ \\
\hline 24 & K. E. Newcomer & How does program performance assessment affect program \\
\hline
\end{tabular}


Construção de Conhecimento sobre o Tema Avaliação de Desempenho da Comunicação em Órgãos Públicos: Uma Análise da Literatura Internacional

\begin{tabular}{|c|l|l|}
\hline $\mathbf{2 5}$ & $\begin{array}{l}\text { A. R. Rezaei; T. Celik; Y. } \\
\text { Baalousha }\end{array}$ & Performance measurement in a quality management system \\
\hline $\mathbf{2 6}$ & $\begin{array}{l}\text { J. Al-Kassab; Z. M. } \\
\text { Ouertani; G. Schiuma; A. } \\
\text { Neely }\end{array}$ & Information visualization to support management decisions \\
\hline $\mathbf{2 7}$ & $\begin{array}{l}\text { P. Whiteley.; H. D. Clarke; } \\
\text { D. Sanders; M. Stewart }\end{array}$ & $\begin{array}{l}\text { Why Do Voters Lose Trust in Governments? Public Perceptions } \\
\text { of Government Honesty and Trustworthiness in Britain 2000- } \\
\text { 2013 }\end{array}$ \\
\hline $\mathbf{2 8}$ & J. C. Zhang; Y. C. Chen & $\begin{array}{l}\text { Enhancing open government information performance: a study of } \\
\text { institutional capacity and organizational arrangement in China }\end{array}$ \\
\hline $\mathbf{2 9}$ & P. Q. Radebe. & $\begin{array}{l}\text { Managers' Perceptions of the Performance Appraisal System in } \\
\text { the Local Municipality of Gauteng Province in South Africa }\end{array}$ \\
\hline
\end{tabular}

Quadro 1 - Banco de autores e citações do PB - 29 artigos e 67 autores

Fonte: Autores da pesquisa (2017)

Após a verificação do alinhamento de acordo com as delimitações do pesquisador, o PB foi definido, o qual se encontra na Tabela 2. A partir da conclusão da seleção do PB, é realizada a análise bibliométrica do conjunto de artigos do PB e referências e a análise de conteúdo das variáveis avançadas.

\section{ANÁLISE DOS RESULTADOS}

Nesta seção será apresentada a análise bibliométrica do $\mathrm{PB}$ e será evidenciada quanto: a) à relevância dos autores; b) ao reconhecimento científico dos artigos; c) à análise dos periódicos que mais publicaram artigos (ENSSLIN et al., 2015). Além disso, será apresentada também a análise das variáveis de conteúdo avançadas, sob dois aspectos: a) "Medição e Gestão de Desempenho" propostas por Melnyk et al., (2014); b) quanto às variáveis avançadas relativas aos 4 (quatro) caminhos evolutivos propostas por Srimai, Radford e Wright (2011). Os conceitos relativos às alíneas "a" e "b" das variáveis de conteúdo avançadas já foram apresentados na fundamentação teórica deste trabalho.

\subsection{Bibliometria: Variáveis Básicas}

Foi realizada análise dos autores dos artigos do PB e das referências, para se verificar se algum autor era destaque nesse tipo de publicação. Entretanto, verificou-se que dos 29 artigos do $\mathrm{PB}$, escritos por 67 autores, A. Johnsen escreveu dois artigos e J. Melkers também escreveu dois artigos; os demais artigos foram escritos por autores diferentes.

Age Johnsen escreveu os artigos "What Does 25 Years of Experience Tell Us about the State of Performance Measurement in Public Policy and Management?", publicado em 2005 e "Distinctive research patterns on public sector performance measurement of public administration and accounting disciplines", com outros dois autores, publicado em 2008. Johnsen é professor de Política Pública do Departamento de Gestão Pública na Oslo e Akershus University College de Ciências Aplicadas. Ele já trabalhou como pesquisador na Agder Research em Kristiansand e na Escola Norueguesa de Economia e Administração de Empresas em Bergen, ambas na Noruega, e na Universidade de Edimburgo, Escócia e é Professor Associado da University College de Oslo. Sua área de pesquisa está voltada para o planejamento estratégico e gestão, gestão de desempenho e avaliação de desempenho no setor público.

Julia Melkers escreveu os artigos "Models of performance-measurement use in local governments: Understanding budgeting, communication, and lasting effects" com mais um autor, publicado em 2005 e "On the road to Improved Performance: Changing Organizational Communication Through Performance Management" sozinha, publicado em 2006. Ela é professora da Escola de Políticas Públicas do Instituto de Tecnologia da Georgia, da Universidade Estadual da Georgia, da Universidade de Illinois, em Chicago e da Universidade do Alasca, todas nos Estados Unidos, onde ela ensina gestão pública, teoria da organização, avaliação de desempenho e política de ciência e tecnologia. Ela realiza pesquisas nas áreas de gestão pública, teoria organizacional e política de ciência e tecnologia. Sua área de pesquisa primária aborda o desenvolvimento e a utilização de medição de desempenho nas organizações públicas.

Nos 23 artigos das referências, escritos por 38 autores, apenas dois artigos são escritos pelos mesmos autores (R. S. Kaplan e D. P. Norton); eles escreveram os artigos "Using the Balanced Scorecard as a Strategic Management System", publicado em 1996 e que em abril/2016 contava com 6.358 citações e "The balanced scorecard - measures that drive performance", publicado em 2005. Robert S. Kaplan (nascido em 1940) é professor da Fundação Baker na Harvard Business School (HBS), dos Estados Unidos, e co- 
Construção de Conhecimento sobre o Tema Avaliação de Desempenho da Comunicação em Órgãos Públicos: Uma Análise da Literatura Internacional

criador, juntamente com David Norton, do método de gestão Balanced Scorecard (BSC) e co-fundador da Balanced Scorecard Collaborative e doutor em Administração de Empresas pela Universidade de Harvard. David P. Norton (nascido em 1941) também é doutor em Administração de Empresas pela Universidade de Harvard e é professor no Departamento de Ciência e Engenharia de materiais da Universidade da Flórida.

Os demais artigos foram escritos por autores diferentes. Assim, nenhum autor se destacou na produção de artigos científicos sobre o tema em questão, seja nos artigos do PB, seja nos artigos das referências.

\subsubsection{Reconhecimento científico dos artigos}

Os 29 artigos do PB contemplam um total de 3.042 citações. Estão listados na Figura 4, os artigos com mais de 100 citações (9 artigos). O artigo mais citado "An institutional perspective on performance measurement and management in the 'new public sector'", publicado em 2000, tinha 682 citações (22\% do total de citações) em abril de 2016, cujos autores são Brignall e Modell, conforme pesquisado no Google Scholar. Ele trata das implicações institucionais para implementação de gestão e medição de desempenho multidimensional no setor público. A figura 3 traz os 10 artigos mais citados do PB.

Figura 3 - Número de citações dos artigos mais citados no PB

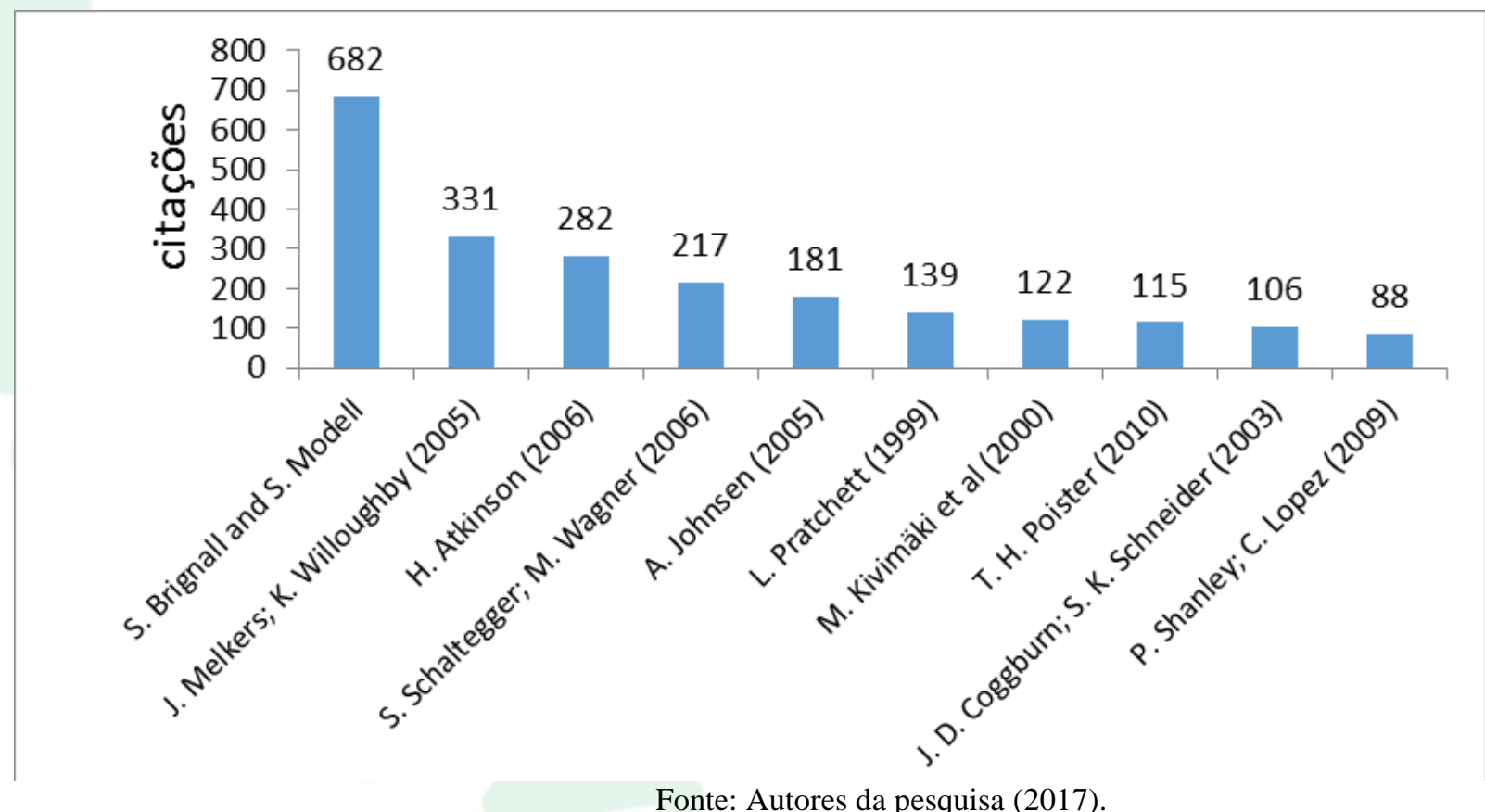

\subsubsection{Análise dos periódicos que mais publicaram artigos}

Em relação aos 29 artigos do $\mathrm{PB}$, o periódico "Public Administration Review" publicou 4 artigos e os periódicos "Management Accounting Research" e "Public Performance \& Management Review" publicaram, cada um, dois artigos do Portfólio
Bibliográfico. Em relação aos 23 artigos das referências, apenas quatro periódicos publicaram dois artigos cada um. São eles: "International Journal of Operation and Production Management"; "Public Performance and Management Review"; "Harvard Business Review" e "Public Relations Review". A Figura 4 apresenta os periódicos que publicaram mais de um artigo do PB e das referências. 
Construção de Conhecimento sobre o Tema Avaliação de Desempenho da Comunicação em Órgãos Públicos: Uma Análise da Literatura Internacional

Figura 4 - Número de publicações de artigos do PB e referências por periódico

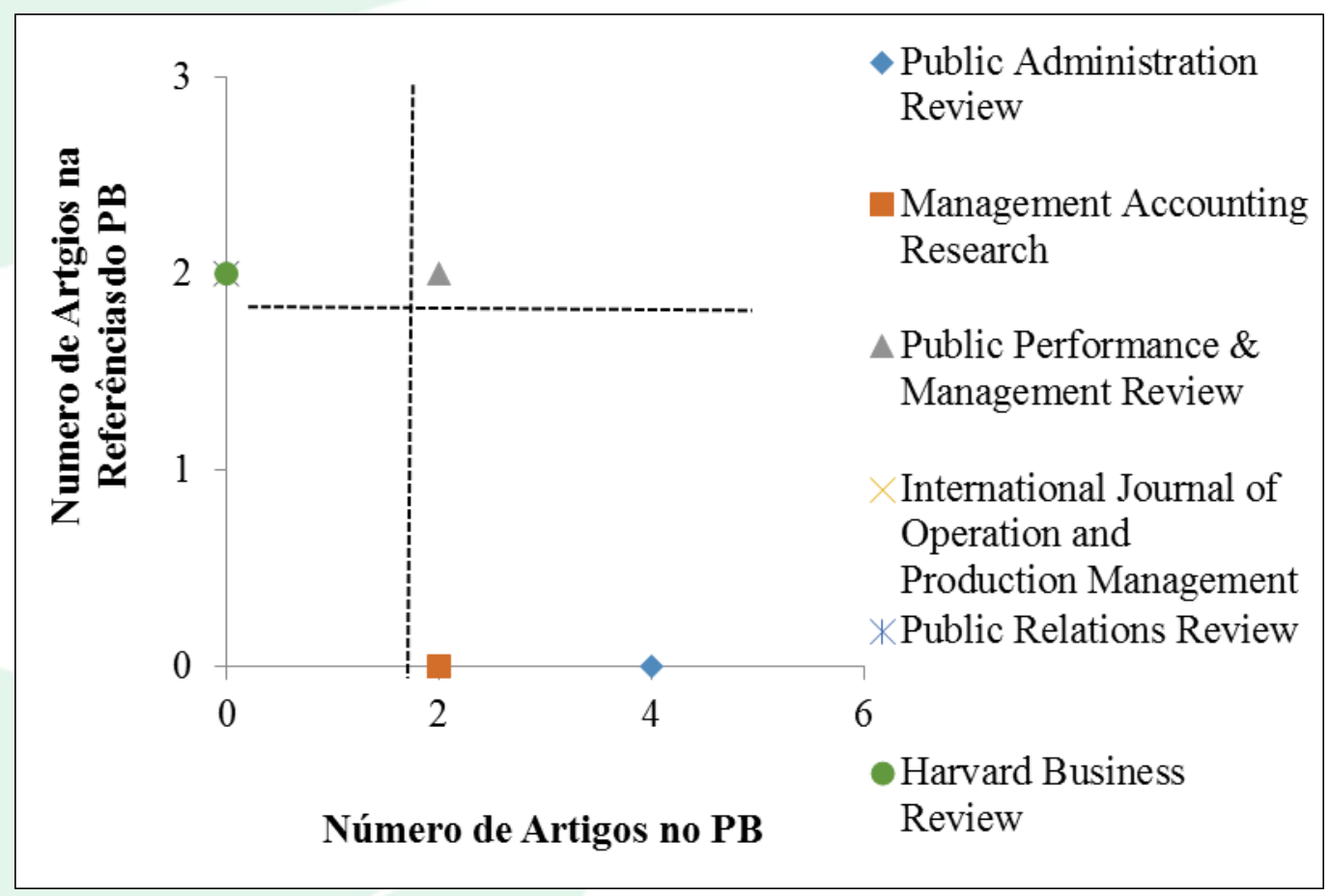

Fonte: Autores da pesquisa (2017).

Percebe-se que o periódico "Public Performance \& Management Review" destacou-se por ter publicado dois artigos do Portifólio Bibliográfico e dois artigos das Referências. Ressalta-se, ainda, que este periódico possui fator de impacto SJR 0,907 e JCR 0,909, o que demonstra ser um periódico relevante e de reconhecimento científico. Outro destaque é o periódico "Public Administration Review", que publicou 4 (quatro) artigos do PB e possui fator de impacto SJR 2,530 e JCR 2,636, bastante altos e de grande relevância.

\subsection{Análise Das Variáveis Avançadas}

Seguindo a classificação proposta por Melnyk et al., (2014), os 29 artigos do Portifólio Bibliográfico foram analisados sob o ponto de vista de tratarem de mensuração de desempenho ou gestão de desempenho. A gestão de desempenho ultrapassa os limites da mensuração de desempenho, porquanto além de medir, avalia as diferenças entre os resultados reais e os desejados, identifica e sinaliza as diferenças críticas e introduz ações corretivas. A classificação dos artigos está disposta no Quadro 2.

\begin{tabular}{|l|c|c|}
\hline \multicolumn{1}{|c|}{ ARTIGO } & $\begin{array}{c}\text { MENSURAÇÃO DE } \\
\text { DESEMPENHO }\end{array}$ & $\begin{array}{c}\text { GESTÃO DE } \\
\text { DESEMPENHO }\end{array}$ \\
\hline $\begin{array}{l}\text { 1. A Balanced Scorecard Approach to Public Relations Management } \\
\text { Assessment }\end{array}$ & $\mathrm{X}$ \\
\hline $\begin{array}{l}\text { 2. An empirical study of key elements of total quality-based } \\
\text { performance measurement systems: A case study approach in the } \\
\text { service industry sector }\end{array}$ & $\mathrm{X}$ \\
\hline $\begin{array}{l}\text { 3. An institutional perspective on performance measurement and } \\
\text { management in the 'new public sector }\end{array}$ & $\mathrm{X}$ & \\
\hline $\begin{array}{l}\text { 4. Communication as a determinant of organization innovation } \\
\text { 5. Communication Gaps in Disaster Management: Perceptions by } \\
\text { Experts from Governmental and Non-Governmental Organizations }\end{array}$ & $\mathrm{X}$ & \\
\hline
\end{tabular}


Construção de Conhecimento sobre o Tema Avaliação de Desempenho da Comunicação em Órgãos Públicos: Uma Análise da Literatura Internacional

\begin{tabular}{|c|c|c|}
\hline $\begin{array}{l}\text { 6. Creating a Performance Culture? Performance-based Pay in the } \\
\text { Australian Public Service }\end{array}$ & $\mathrm{X}$ & \\
\hline $\begin{array}{l}\text { 7. Distinctive research patterns on public sector performance } \\
\text { measurement of public administration and accounting disciplines }\end{array}$ & $\mathrm{X}$ & \\
\hline $\begin{array}{l}\text { 8. Enhancing open government information performance: a study of } \\
\text { institutional capacity and organizational arrangement in China }\end{array}$ & $\mathrm{X}$ & \\
\hline $\begin{array}{l}\text { 9. How does program performance assessment affect program } \\
\text { management in the federal government? }\end{array}$ & & $\mathrm{X}$ \\
\hline 10. Information visualization to support management decisions & & $\mathrm{X}$ \\
\hline $\begin{array}{l}\text { 11. Integrative management of } \\
\text { measurement and reporting }\end{array}$ & & $\mathrm{X}$ \\
\hline $\begin{array}{l}\text { 12. Managers' Perceptions of the Performance Appraisal System in the } \\
\text { local Municipality of Gauteng Province in South Africa }\end{array}$ & $\mathrm{X}$ & \\
\hline $\begin{array}{l}\text { 13. New Political Governance in Westminster Systems: Impartial } \\
\text { Public Administration and Management Performance at Risk }\end{array}$ & $\mathrm{X}$ & \\
\hline $\begin{array}{l}\text { 14. New technologies and modernization of local government: an } \\
\text { analysis of biases and constraints }\end{array}$ & NÃO & NÃO \\
\hline $\begin{array}{l}\text { 15. On the road to improved performance: changing organizational } \\
\text { communication through Performance Management }\end{array}$ & $\mathrm{X}$ & \\
\hline $\begin{array}{l}\text { 16. Out of the Loop: Why Research Rarely Reaches Policy Makers and } \\
\text { the Public and What Can be Done? }\end{array}$ & $\mathrm{X}$ & \\
\hline $\begin{array}{l}\text { 17. Performance management and accountability in complex public } \\
\text { programmes }\end{array}$ & $\mathrm{X}$ & \\
\hline 18. Performance measurement in a quality management system & $\mathrm{X}$ & \\
\hline $\begin{array}{l}\text { 19. Strategic Management and Public Service Performance: The Way } \\
\text { Ahead }\end{array}$ & $\mathrm{X}$ & \\
\hline 20. Strategy implementation: a role for the balanced scorecard? & $\mathrm{X}$ & \\
\hline $\begin{array}{l}\text { 21. The Future of Strategic Planning in the Public Sector: Linking } \\
\text { Strategic Management and Performance }\end{array}$ & & $\mathrm{X}$ \\
\hline $\begin{array}{l}\text { 22. The judgmental effects of management communications and a fifth } \\
\text { balanced scorecard category on performance evaluation }\end{array}$ & & $\mathrm{X}$ \\
\hline $\begin{array}{l}\text { 23. The judgmental effects of strategy maps in balanced scorecard } \\
\text { performance evaluations }\end{array}$ & & $\mathrm{X}$ \\
\hline $\begin{array}{l}\text { 24. The Quality of Management and Government Performance: An } \\
\text { Empirical Analysis of the American States }\end{array}$ & $\mathrm{X}$ & \\
\hline $\begin{array}{l}\text { 25. The use of performance measurement systems in the public sector: } \\
\text { Effects on performance }\end{array}$ & $\mathrm{X}$ & \\
\hline $\begin{array}{l}\text { 26. Why Do Voters Lose Trust in Governments? Public Perceptions of } \\
\text { Government Honesty and Trustworthiness in Britain 2000-2013 }\end{array}$ & $\mathrm{X}$ & \\
\hline 27. Why Is Performance Management Broken? & NÃO & NÃO \\
\hline $\begin{array}{l}\text { 28. What Does } 25 \text { Years of Experience Tell Us About the State of } \\
\text { Performance Measurement in Public Policy and Management? }\end{array}$ & & $\mathrm{X}$ \\
\hline $\begin{array}{l}\text { 29. Models of Performance-Measurement Use in Local Governments: } \\
\text { Understanding Budgeting, Communication, and Lasting Effects. }\end{array}$ & & $\mathrm{X}$ \\
\hline
\end{tabular}

Quadro 2 - Classificação dos artigos do PB de acordo com as variáveis "Mensuração de desempenho" e "Gestão de desempenho" 
Dos 29 artigos do PB, dois mostraram-se teóricos e não foram classificados de acordo com as variáveis Mensuração ou Gestão de Desempenho. Os outros 27 artigos foram classificados de acordo com as duas variáveis e constatou-se que 17 tratavam-se de mensuração de desempenho e 10 de gestão de desempenho.

A maior parte dos artigos parte de uma visão realista, que delega aos consultores e pesquisadores a função de selecionar o modelo teórico a ser usado, a partir de este coletar os dados em determinado contexto de gestão para que então se proponha uma solução ótima, capaz de solucionar o problema proposto e ser replicado em outros contexto (ROY, 1993).
Seguindo a classificação proposta por Srimai, Radford e Wright (2011), os modelos de avaliação de desempenho passaram por um caminho evolutivo a partir do início do século XX, quando o desempenho limitava-se à medição. Segundo os autores, a partir do desenvolvimento dos sistemas de avaliação de desempenho e as novas demandas do mercado, a mensuração de desempenho percorre quatro caminhos evolutivos, que são: a) Transição de operações para as orientações estratégicas; b) Transição de medição para domínios de gestão; c) Transição de estático para perspectivas dinâmicas; d) Transição do acionista aos valores das partes interessadas (stakeholders), conforme Quadro 3.

\begin{tabular}{|c|c|c|c|c|}
\hline Artigo & $\begin{array}{c}\text { Transição de } \\
\text { operaçôes para } \\
\text { as orientações } \\
\text { estratégicas }\end{array}$ & $\begin{array}{l}\text { Transição de } \\
\text { medição para } \\
\text { domínios de } \\
\text { gestão }\end{array}$ & $\begin{array}{c}\text { Transição de estático } \\
\text { para perspectivas } \\
\text { dinâmicas }\end{array}$ & $\begin{array}{c}\text { Transição do acionista } \\
\text { aos valores das partes } \\
\text { interessadas } \\
\text { (stakeholders) }\end{array}$ \\
\hline $\begin{array}{l}\text { 1. A Balanced Scorecard } \\
\text { Approach to Public Relations } \\
\text { Management Assessment }\end{array}$ & & & & $X$ \\
\hline $\begin{array}{l}\text { 2. An empirical study of key } \\
\text { elements of total quality- } \\
\text { based } \\
\text { measurement systems: A } \\
\text { case study approach in the } \\
\text { service industry sector }\end{array}$ & $X$ & & & \\
\hline $\begin{array}{l}3 . \quad \text { An } \\
\text { perspective on performance } \\
\text { measurement } \\
\text { management in the 'new } \\
\text { public sector' }\end{array}$ & & & & $X$ \\
\hline $\begin{array}{l}\text { 4. Communication as a } \\
\text { determinant of organization } \\
\text { innovation }\end{array}$ & $X$ & & & \\
\hline $\begin{array}{l}\text { 5. Communication Gaps in } \\
\text { Disaster Management: } \\
\text { Perceptions by Experts from } \\
\text { Governmental and Non- } \\
\text { Governmental Organizations }\end{array}$ & $X$ & & & \\
\hline $\begin{array}{l}\text { 6. Creating a Performance } \\
\text { Culture? Performance-based } \\
\text { Pay in the Australian Public } \\
\text { Service }\end{array}$ & $\mathrm{X}$ & & & \\
\hline $\begin{array}{l}\text { 7. Distinctive research } \\
\text { patterns on public sector } \\
\text { performance measurement of } \\
\text { public administration and } \\
\text { accounting disciplines }\end{array}$ & $X$ & & & \\
\hline $\begin{array}{l}8 . \text { Enhancing open } \\
\text { government information } \\
\text { performance: a study of } \\
\text { institutional capacity and } \\
\text { organizational arrangement } \\
\text { in China }\end{array}$ & & & & $X$ \\
\hline 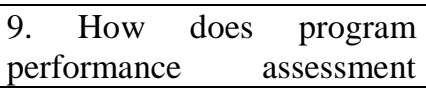 & & $X$ & & \\
\hline
\end{tabular}


Construção de Conhecimento sobre o Tema Avaliação de Desempenho da Comunicação em Órgãos Públicos: Uma Análise da Literatura Internacional

\begin{tabular}{|c|c|c|c|c|}
\hline $\begin{array}{l}\text { affect program management } \\
\text { in the federal government? }\end{array}$ & & & & \\
\hline $\begin{array}{l}\text { 10. Information visualization } \\
\text { to support management } \\
\text { decisions }\end{array}$ & & & $X$ & \\
\hline $\begin{array}{lr}\text { 11. Integrative } & \text { management } \\
\text { of } & \text { sustainability } \\
\text { performance, } & \text { measurement } \\
\text { and reporting } & \\
\end{array}$ & $X$ & & & \\
\hline $\begin{array}{l}\text { 12. Managers' Perceptions of } \\
\text { the Performance Appraisal } \\
\text { System in the local } \\
\text { Municipality of Gauteng } \\
\text { Province in South Africa }\end{array}$ & & $X$ & & \\
\hline $\begin{array}{lr}13 . \quad \text { New Political } \\
\text { Governance in Westminster } \\
\text { Systems: Impartial Public } \\
\text { Administration and } \\
\text { Management Performance at } \\
\text { Risk }\end{array}$ & $X$ & & & \\
\hline $\begin{array}{l}\text { 14. New technologies and } \\
\text { modernization of local } \\
\text { government: an analysis of } \\
\text { biases and constraints }\end{array}$ & NÃO & NÃO & NÃO & NÃO \\
\hline $\begin{array}{l}\text { 15. On the road to improved } \\
\text { performance: changing } \\
\text { organizational } \\
\text { communication through } \\
\text { Performance Management }\end{array}$ & $X$ & & & \\
\hline $\begin{array}{l}\text { 16. Out of the Loop: Why } \\
\text { Research Rarely Reaches } \\
\text { Policy Makers and the Public } \\
\text { and What Can be Done? }\end{array}$ & & & & $X$ \\
\hline $\begin{array}{lr}17 . & \text { Performance } \\
\text { management } & \text { and } \\
\text { accountability in complex } \\
\text { public programmes }\end{array}$ & $X$ & & & \\
\hline $\begin{array}{l}18 . \\
\text { measurement in a quality } \\
\text { management system }\end{array}$ & $X$ & & & \\
\hline 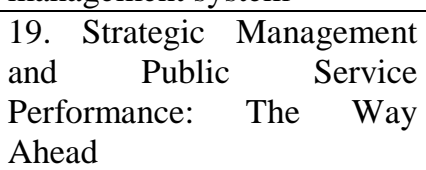 & $X$ & & & \\
\hline $\begin{array}{l}\text { 20. Strategy implementation: } \\
\text { a role for the balanced } \\
\text { scorecard? }\end{array}$ & $X$ & & & \\
\hline $\begin{array}{l}\text { 21. The Future of Strategic } \\
\text { Planning in the Public } \\
\text { Sector: Linking Strategic } \\
\text { Management } \\
\text { Performance }\end{array}$ & & $X$ & & \\
\hline $\begin{array}{l}\text { 22. The judgmental effects of } \\
\text { management } \\
\text { communications and a fifth } \\
\text { balanced scorecard category } \\
\text { on performance evaluation }\end{array}$ & & $X$ & & \\
\hline
\end{tabular}


Construção de Conhecimento sobre o Tema Avaliação de Desempenho da Comunicação em Órgãos Públicos: Uma Análise da Literatura Internacional

\begin{tabular}{|l|l|l|l|l|}
\hline $\begin{array}{l}\text { 23. The judgmental effects of } \\
\text { strategy maps in balanced } \\
\text { scorecard performance } \\
\text { evaluations }\end{array}$ & X & & \\
\hline $\begin{array}{l}\text { 24. The Quality of } \\
\text { Management and } \\
\text { Government Performance: } \\
\text { An Empirical Analysis of the }\end{array}$ & & & & \\
American States & & & & \\
\hline $\begin{array}{l}\text { 25. The use of performance } \\
\text { measurement systems in the } \\
\text { public sector: Effects on } \\
\text { performance X }\end{array}$ & X & & & \\
\hline $\begin{array}{l}\text { 26. Why Do Voters Lose } \\
\text { Trust in Governments? } \\
\text { Public Perceptions of } \\
\text { Government Honesty and } \\
\text { Trustworthiness in Britain } \\
\text { 2000-2013 X }\end{array}$ & & & \\
\hline $\begin{array}{l}\text { 27. Why Is Performance } \\
\text { Management Broken? }\end{array}$ & NÃO & NÃO & & \\
\hline $\begin{array}{l}\text { 28. What Does 25 Years of } \\
\text { Experience Tell Us About } \\
\text { the State of Performance } \\
\text { Measurement in Public } \\
\text { Policy and Management? }\end{array}$ & & & & \\
\hline $\begin{array}{l}\text { 29. Models of Performance- } \\
\text { Measurement Use in Local } \\
\text { Governments: Understanding } \\
\text { Budgeting, Communication, } \\
\text { and Lasting Effects. }\end{array}$ & & & & \\
\hline
\end{tabular}

Quadro 3 - Classificação dos artigos do PB de acordo com as variáveis "Mensuração de desempenho" e "Gestão de desempenho"

Fonte: Autores da Pesquisa (2017)

Analisando os 29 artigos, constatamos que dois artigos são eminentemente teóricos e não foram classificados de acordo com as variáveis acima. Dos 27 artigos restantes, 15 foram classificados como sendo de "Transição de operações para as orientações estratégicas"; 6 artigos foram classificados como sendo de "Transição de medição para domínios de gestão"; 1 artigo foi classificado como sendo de "Transição de estático para perspectivas dinâmicas" e 5 artigos foram classificados como sendo de "Transição do acionista aos valores das partes interessadas (stakeholders)".

A partir desses resultados constata-se que novamente a maior parte dos artigos ainda encontramse em estágios iniciais dos caminhos evolutivos, fazendo uso de abordagens que pressupõem que os decisores conduzem suas atividades em plena racionalidade, isentos de percepções e aspectos subjetivos.

\section{CONCLUSÕES}

Este estudo teve como objetivo mapear na literatura internacional o fragmento da literatura que trata do tema Avaliação de Desempenho da Comunicação em Órgãos Públicos, com a aplicação do instrumento de intervenção Knowledge Development Process - Constructivist (ProKnow-C).

Para atingir o principal objetivo da pesquisa, foram estipulados três objetivos específicos:

(i) selecionar um Portifólio Bibliográfico alinhado com a percepção dos pesquisadores sobre o tema Avaliação de Desempenho da Comunicação em Órgãos Públicos que se deu ao utilizar o instrumento ProKnow-C foi possível selecionar um PB composto por 29 artigos, alinhados ao tema de pesquisa e relevantes por seu reconhecimento cientifico.

(ii) realizar a análise bibliométrica do Portifólio Bibliográfico selecionado e das suas referências, identificando os autores que mais escrevem e os periódicos que mais publicam sobre o tema da 
pesquisa, os artigos que possuem maior reconhecimento da comunidade científica: $O$ destaque em termos de autores está no artigo que consta nas referências, de autoria de R. S. Kaplan e D. P. Norton, publicado em 1996, "Using the Balanced Scorecard as a Strategic Management System", que conta com 6.358 citações na época da pesquisa. Os periódicos que mais publicaram artigos são, "Public Performance \& Management Review" com dois artigos do PB e dois artigos nas referências. Outro destaque é o periódico "Public Administration Review", que publicou quatro artigos do PB. Em relação ao reconhecimento científico, destaca-se no PB o artigo "An institutional perspective on performance measurement and management in the "new public sector"', publicado em 2000, o qual apresenta 682 citações (22\% do total de citações), cujos autores são Brignall e Modell.

(iii) realizar análise de conteúdo avançada dos artigos do Portifólio Bibliográfico, identificando em que nível eles tratam o tema Avaliação de Desempenho (duas análises avançadas). Em relação à variável de conteúdo avançada Mensuração ou Gestão de Desempenho, percebeu-se que 17 artigos do PB (63\%) foram classificados como de mensuração de desempenho e 37\% (10 artigos) foram classificados como de gestão de desempenho, ou seja, a avaliação de desempenho ainda é utilizada muito mais para medir do que para gerenciar a empresa ou órgão público. Se tratando dos quatro caminhos evolutivos, 15 artigos (55\%) foram classificados como sendo de "Transição de operações para as orientações estratégicas"; 6 artigos (22\%) foram classificados como sendo de "Transição de medição para domínios de gestão"; 1 artigo (4\%) foi classificado como sendo de "Transição de estático para perspectivas dinâmicas" e 5 artigos (19\%) foram classificados como sendo de "Transição do acionista aos valores das partes interessadas (stakeholders)". As duas variáveis de conteúdo avançadas apresentaram valores que indicam que a maioria dos artigos tipificam situações onde a avaliação de desempenho não ultrapassa a barreira da medição ou avaliação de objetivos operacionais.

A partir da análise dos resultados percebe-se que existem lacunas que podem promover avanços na área de conhecimento, são elas:

(i) A utilização de metodologias construtivistas de Avaliação de Desempenho, que levem em conta as peculiaridades e especificidades de cada contexto de gestão da comunicação em órgãos públicos, a partir das preferências e valores dos gestores;

(ii) A incorporação de indicadores estratégicos e táticos, para evidenciar o desempenho dos processos de comunicação em órgãos públicos; e, (iii) A realização de modelos que atendam os pressupostos dos sistemas de gestão de desempenho Melnyk et al., (2014), levando em conta os estágios mais avançados da Avaliação de Desempenho como proposto por Srimai, Radford e Wright (2011).

Como limitações desta pesquisa pode-se destacar: (i) a busca bibliográfica restringiu-se aos artigos publicados em periódicos científicos indexados nas seis bases de dados referenciadas; e, (ii) a exclusão de artigos científicos que não encontravam-se disponíveis por meio de acesso aberto.

Para estudos futuros, sugere-se a expansão desta pesquisa, seja por inclusão de outras bases de dados, novas palavras chave ou limite temporal. Visando identificar maior participação dos decisores na formulação e aplicação de metodologias de Avaliação de Desempenho da Comunicação em Órgãos Públicos.

\section{REFERÊNCIAS}

Beuren, I. M. (2003). Trajetória da construção de um trabalho monográfico em contabilidade. Como elaborar trabalhos monográficos em contabilidade: Teoria e prática, 2: 46-75.

Boyne, G. A., \& Walker, R. M. (2010). Strategic management and public service performance: The way ahead. Public Administration Review, accounting research, 11: 281-306.

70:185-s192.

Brignall, S., \& Modell, S. (2000). An institutional perspective on performance measurement and management in the 'new public sector'. Management

Castro, C. D. M. (1977). A prática da pesquisa. McGraw-Hill.

Creswell, J. W. (2010). Projeto de pesquisa métodos qualitativo, quantitativo e misto. In Projeto de pesquisa métodos qualitativo, quantitativo e misto. Artmed.

Dutra, A., Ripoll-Feliu, V. M., Fillol, A. G., Ensslin, S. R., \& Ensslin, L. (2015). The construction of knowledge from the scientific literature about the theme seaport performance evaluation. International Journal of Productivity and Performance Management, 64: 243-269.

Ensslin, L., Giffhorn, E., Ensslin, S. R., Petri, S. M., \& Vianna, W. B. (2010). Avaliação do desempenho de empresas terceirizadas com o uso da 
metodologia multicritério de apoio à decisãoconstrutivista. Pesquisa Operacional, 30: 125-152.

Ensslin, L., Ensslin, S. R., \& Pinto, H. D. M. (2013). Processo de investigação e Análise bibliométrica: Avaliação da Qualidade dos Serviços Bancários. Revista de Administração Contemporânea, 17: 325349.

Ensslin, L., Dutra, A., Ensslin, S. R., Chaves, L. C., \& Dezem, V. (2015). Research Process for Selecting a Theoretical Framework and Bibliometric Analysis of a Theme: Illustration for the Management of Customer Service in a Bank. Modern Economy, 6: 782.

Ensslin, L., Dutra, A., Martins, R. P., \& Dezem, V. (2016). Modelo Construtivista para Apoiar o Processo de Gestão da Universidade Federal de Tocantins. Revista Ibero-Americana de Estratégia, 15: 122 .

Fleisher, C. S., \& Mahaffy, D. (1997). A balanced scorecard approach to public relations management assessment. Public Relations Review, 23: 117-142.

Jan van Helden, G., Johnsen, Å. \& Vakkuri, J. (2008). Distinctive research patterns on public sector performance measurement of public administration and accounting disciplines. Public Management Review, 10: 641-651.

Johnsen, $\AA$. (2005). What does 25 years of experience tell us about the state of performance measurement in public policy and management? Public Money and Management, 25: 9-17.

Kaplan, R. S., \& Norton, D. P. (2005). The balanced scorecard: measures that drive performance. Harvard business review, 8: 172.

Kaplan, R. S., \& Norton, D. P. (1996). Using the balanced scorecard as a strategic management system.

Kivimäki, M., Länsisalmi, H., Elovainio, M., Heikkilä, A., Lindström, K., Harisalo, R., \& Puolimatka, L. (2000). Communication as a determinant of organizational innovation. $R \& D$ Management, 30: $33-42$.

Melkers, J. (2006). On the road to improved performance. Public Performance \& Management Review, 30: 73-95.

Melnyk, S. A., Bititci, U., Platts, K., Tobias, J., \& Andersen, B. (2014). Is performance measurement and management fit for the future? Management Accounting Research, 25: 173-186.
Neely, A., Gregory, M., \& Platts, K. (1995). Performance measurement system design: a literature review and research agenda. International journal of operations \& production management, 15: 80-116.

Palttala, P., Boano, C., Lund, R., \& Vos, M. (2012). Communication gaps in disaster management: Perceptions by experts from governmental and non-governmental organizations. Journal of Contingencies and Crisis Management, 20: 2-12.

Pulakos, E. D., \& O'LEARY, R. S. (2011). Why is performance management broken?. Industrial and Organizational Psychology, 4: 146-164.

Radebe, P. Q. (2015). Managers' Perceptions of the Performance Appraisal System in the Local Municipality of Gauteng Province in South Africa. Mediterranean Journal of Social Sciences, 6: 175.

Rosa, M. M., Ensslin, S. R., Petri, S. M., \& Ensslin, L. (2015). Avaliação de Desempenho de Políticas Públicas: Construção do Conhecimento com Base na Literatura Internacional. Revista IberoAmericana de Estratégia, 14: 110.

Roy, B. (1993). Decision science or decision-aid science? European journal of operational research, 66: 184-203.

Sinclair, D., \& Zairi, M. (2001). An empirical study of key elements of total quality-based performance measurement systems: A case study approach in the service industry sector. Total Quality Management, 12: 535-550.

Srimai, S., Radford, J., \& Wright, C. (2011). Evolutionary paths of performance measurement: an overview of its recent development. International Journal of Productivity and Performance Management, 60: 662-687.

Triviños, A. N. S. (2015). Introdução à pesquisa em ciências sociais: a pesquisa qualitativa em educação. O positivismo; a fenomenologia; $o$ marxismo. In Introdução à pesquisa em ciências sociais: a pesquisa qualitativa em educação. $\mathrm{O}$ positivismo; a fenomenologia; o marxismo. Atlas.

Tasca, J.E., Ensslin, L., Ensslin, S.R., \& Alves, B. M. (2010). An approach for selecting a theoretical framework for the evaluation of training programs. Journal of European Industrial Training, 34: 631655.

Zhang, J. C., \& Chen, Y. C. (2015). Enhancing open government information performance: a study of institutional capacity and organizational 
arrangement in China. Chinese Journal of

Communication, 8: 160-176.

Whiteley, P., Clarke, H. D., Sanders, D., \& Stewart, M. (2016). Why Do Voters Lose Trust in Governments? Public Perceptions of Government Honesty and Trustworthiness in Britain 2000-2013. The British Journal of Politics and International Relations, 18: 234-254. 